\title{
Theoretical and experimental considerations regarding to functioning of a combat vehicle shutter's hydraulic actuation system
}

\author{
I Lespezeanu, L Barothi ${ }^{*}$, R Vilau \\ Military Technical Academy, 39-49 George Cosbuc Blvd., Bucharest, Romania \\ *Corresponding author e-mail: barothi_laszlo@yahoo.ro \\ Article history \\ Received 15.06.2017 \\ Accepted 29.08.2017 \\ DOI https://doi.org/10.26825/bup.ar.2017.007
}

\begin{abstract}
The paper proposes a theoretical analysis of kinematic and dynamic performances of several elements in the composition of a combat vehicle shutter's hydraulic system, using LMS AMESim, specialized CAE software.
\end{abstract}

\section{System description}

The project refers to a controlled opening system for a combat vehicle shutters. These shutters are disposed on the ceiling housing armor. Their opening is done with hydraulic cylinders, one for each one.Hydraulic installation scheme was carried out in order to meet the requirements imposed in the development operational project. These requirements are:

- The maximum opening/closing time to not exceed 15 second;

- The system must be provided with a hydraulic discharge element, for manual manipulating in case of damage;

- Hydraulic pump powered at $24 \mathrm{~V}$.

- The mass of a shutter to not exceed $150 \mathrm{~kg}$

The designed actuating system of shutters is a hydraulic system with electrical command. The electricity used to power the system's pump is obtained from additional installed electric generator inside of vehicle or from vehicle batteries. The system's command is realized from an electrical panel. In case of damage, this system allows manual operation of the shutters. components:

The hydraulic system diagram of shutter's actuating (shown in figure 1) has the following 


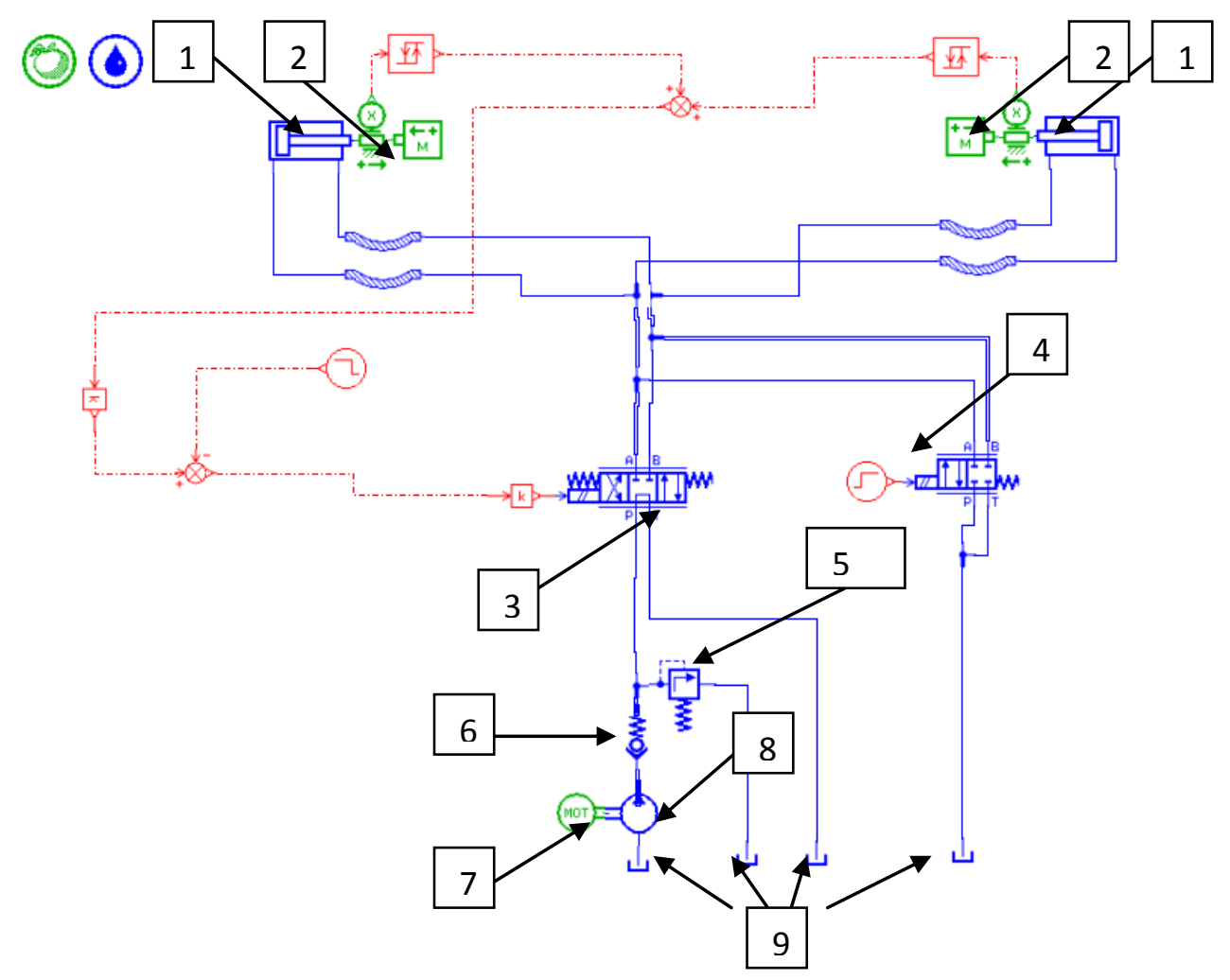

Figure 1

1. Hydraulic cylinder for opening the shutter on the left and right side;

2. Mass equivalent for shutters (left right);

3. The main electrical operated distributor for command of hydraulic cylinders. The distributor has 4 way and 3 positions, the neutral position is when empty the pump discharge;

4. The manually operated distributor, serving unloading cylinders in an emergency case, thus shutters can be opened/ closed. The distributor has 4 way and 2 positions, normal position is „,closed”;

5. Safety valve;

6. Directional valve;

7. $24 \mathrm{~V}$ electric motor, powered by electric generator;

8. Hydraulic pomp with fix capacity;

9. Tank.

Observation: - parts 5, 6, 7, 8, 9 are integrated into single hydraulic equipment called electro-pump group.

\section{Used measurement apparatus}

Data acquisition system consists of a source of energy, connection box, data acquisition card and sensors. (Figure 2.)

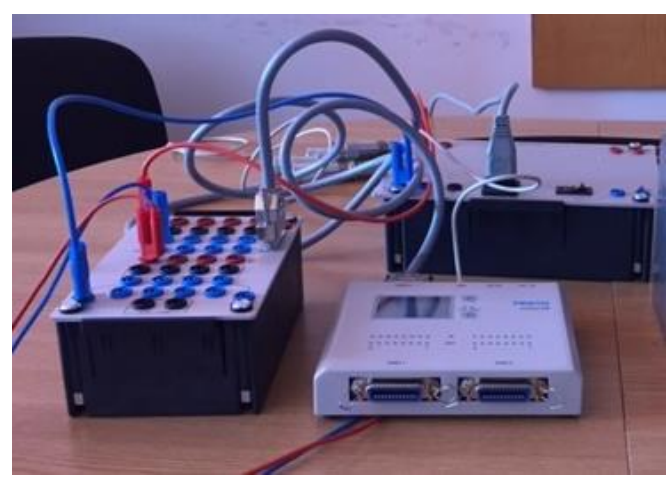

Figure 2 
For hydraulic system testing it was used two sensors; to determine the position of the hydraulic cylinder rod was used a displacement transducer inductive type from Monitran firm with the following technical specifications: Stroke $\pm 0.5 \mathrm{~mm}$ to $\pm 550 \mathrm{~mm}$; Input Voltage $9-24$ VDC (dependent on conditioning unit); Non-Linearity $\pm 0.5 \%$ of full range, (higher specification can be achieved at extra cost); Repeatability Better than $0.1 \%$ Resolution Infinite (dependent on measuring instrument); Frequency Response 3dB @ 180Hz; Vibration Resistance 20g up to 2kHz; Shock Resistance 1000g for 10 milliseconds; Insulation Resistance Above 10M $\Omega$ at 500VDC (between wires and case); Dielectric Strength 500V RMS for one minute; and to determine the pressure from the hydraulic system was used a pressure sensor from WIKA company. The measurement range of pressure transducer is between 0-400 bars, the tension is between the 8-30 $\mathrm{V}$, and the current is between 0-20 mA. (Figure 3 and Figure 4).

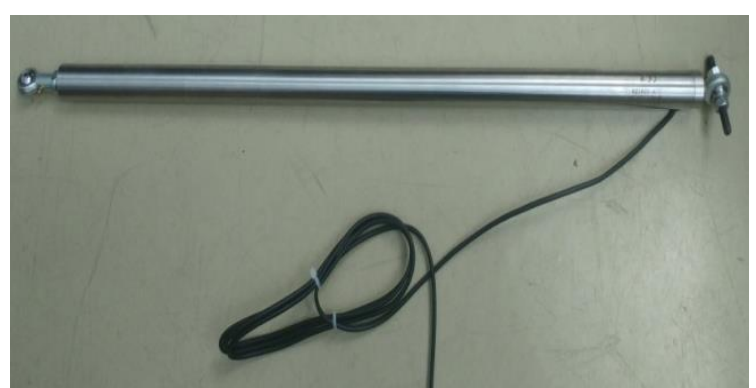

Figure 3

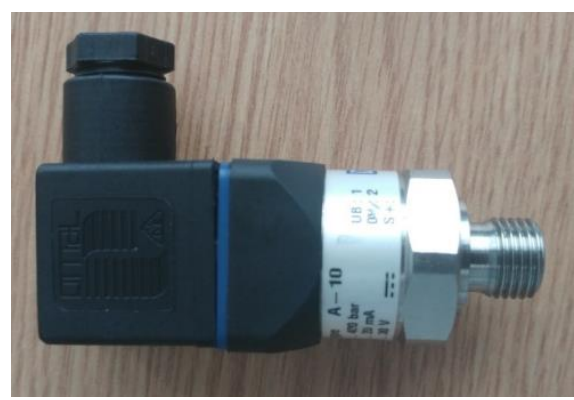

Figure 4

\section{Process simulation with LMS AMESim}

For theoretical validating, that hydraulic system satisfies all the requirements imposed on the project theme, was made an analysis in a special software, on LMS AMESim.

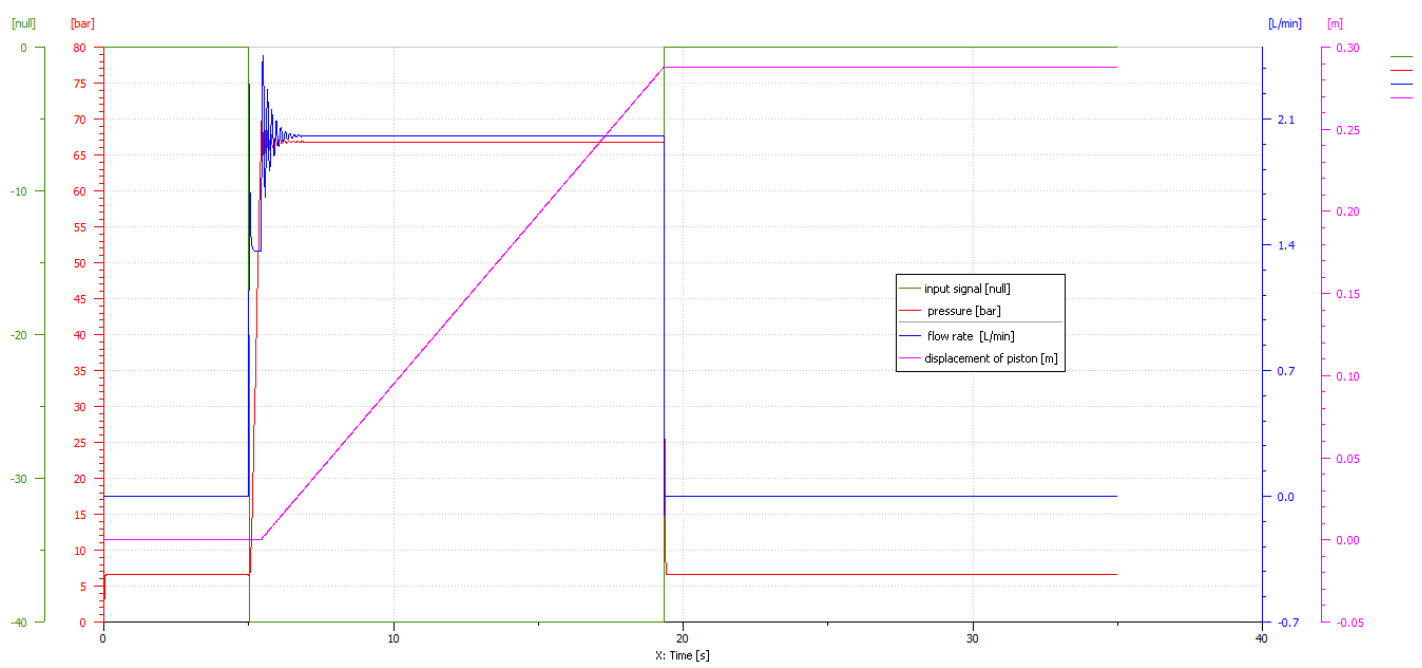

Figure 5

On this graph are represented the command signal variation of hydraulic distributor (green), the variation in movement of the two hydraulic cylinders (purple), the flow at the distributor port (blue) and hydraulic pressure created by hydraulic pump (red). Mention is made of the fact that this graph is valid only at the time of the opening of the shutters. It further notes that at the time of shifting distributor there is a switching period in which both the pressure and flow rate fluctuates. It can be explained that that the distributor does not switch instantly. And at the close of the distributor appears the phenomenon called "hydraulic shock".Fluid flow is constant and has a value of $2 \mathrm{l} / \mathrm{min}$. 
It can be seen that from the moment of opening the distributor, the two cylinders are put into operation. At the moment of $t_{2}=19,6 \mathrm{~s}$ the distributor's signal cuts back to zero position, which means that the shutters are open. That it can be calculated the total shutters opening time, with the relation below. ( $\Delta t=t_{1}-t_{2}=19,6-5=14,6 \mathrm{~s}$ ).It can be seen that there are 5 second of delay, which can be explained that the commandfor distributor was given after 5 seconds, in AMESim program for a better graph view.

The shutter opening/ closing time is respected.

\section{Achieved results}

The designed hydraulic system check was realized with the acquisition system presented above. Displacement transducer is mounted via its shackles once at a fixed bracket located on the mounting plate of the hydraulic cylinder. And the other shackle is mounted on a specially created support for this purpose on the hydraulic cylinders shackle. Pressure sensor is installed in the hydraulic circuit, in parallel, by T shifts and pipe reductions.

Graphs results for change in pressure and movement are listed below. These graphs are made in the moment of opening the shutters. These graphs were trigged which explains the fact that hydraulic cylinders' rod starts to move at $\mathrm{t}=0 \mathrm{~s}$.

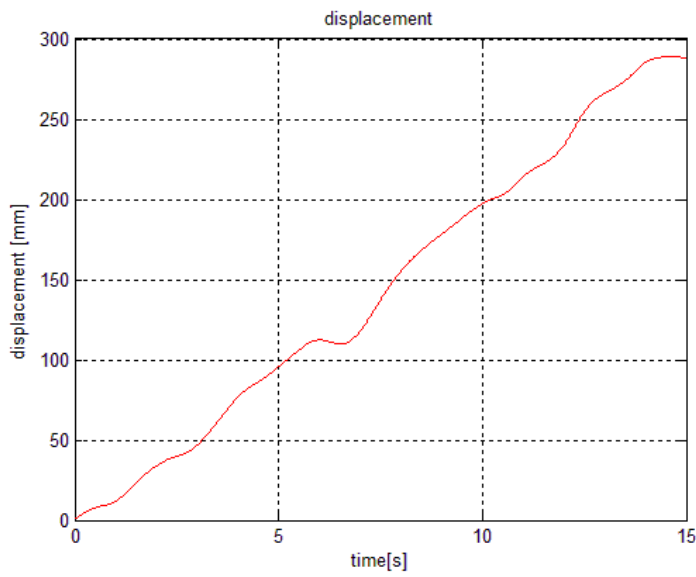

Figure 6

It can be observed on this graphic that hydraulic cylinder reaches to its maximum stoke after 15 seconds which is very close to the theoretical situation. However that does not match the theoretical situation, and it was expected, that displacement is not linear.This can be explained that hydraulic cylinder meets resistance in stroke. At $t=6.7$ seconds shutter sits on place for a short time. Exactly at this point decreases a bit the pressure. These two phenomena are directly related.

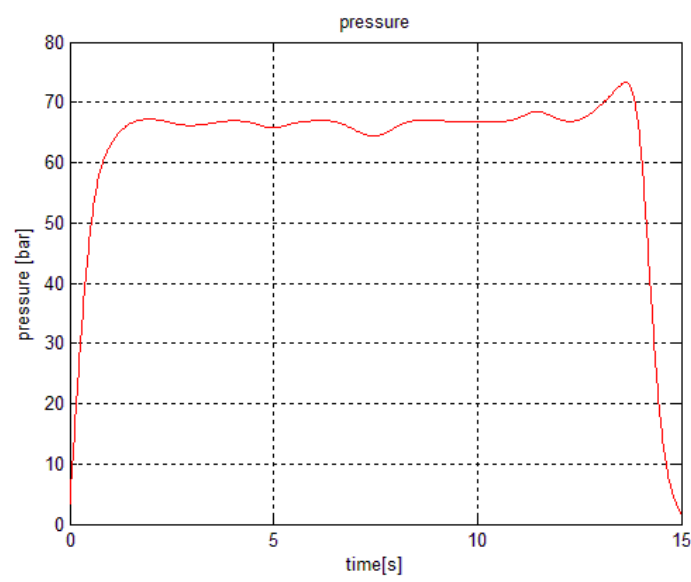

Figure 7 
As same as the displacement the pressure is not linear.It can be observed that, when the hydraulic cylinder has reached the maximum value, the pressure suddenly (hydraulic shock), after that it decreases. This is explained by the fact that the bypass valve (Safety) opens so the pressure decreases and it avoids the destruction of the hydraulic system (6.58296 bars). In addition a few tenths of seconds of delay the hydraulic distributor switches automatically in the neutral position. This is tied into the feedback loop with 2 contacts.

\section{Conclusion}

In order to validate the correct functioning of hydraulic shutters system was used a data acquisition system presented above, which has the following advantages: reasonable price, easy usage and installation of equipment, data acquisition rate corresponding to the needs to surprise the phenomenon. For this system it was necessary to use a filter to avoid electrical noise.

The novelty of the work consists in the fact that it has been developed from zero a new hydraulic system for opening shutters of a combat vehicle and that it has made a theoretical analysis in a CAE program. The main observations about the prototype of the designed hydraulic system are:

- Is not intense requested, so the hydraulic system is not required an oil cooler, for this reason it was not mentioned.

- The hydraulic system is equipped with contacts to limit the hydraulic cylinders' rod stroke, because otherwise the pressure in the system increases a lot. All of this is necessary and the use of a safety valve set at 100 bar.

- In order to meet operational requirements, for opening and closing the shutters manually (in the case of failure of the hydraulic system) the system has provided for an additional 4-way distributor with 2 positions, manually operated.

After testing the prototype it was concluded that the results are very close to the theoretical results made in the CAE program.

\section{References}

[1] Webster J G- The measurement, instrumentation and sensors handbook, Ed. Library of Congress, 1999;

[2] Hao Y X, Quan L, Huang J H-Research on the performance of electro-hydraulic proportional flow valva controlled by active pilot pump, Procedings of the institution of mechanical engineers part EJournal of process Mechanical Engineering, Volume 231, pg 720-731, DOI:10.1177/0954408916632466;

[3] Marinescu M, Ilie C O- Filtering the signal of a measured mechanical parameter, $10^{\text {th }}$ International Conference on COMMUNICATIONS (COMM), May 29-31, 2014, Bucharest, Romania, Conference Proceedings, AGIR Publishing House, pp. 85-88, ISBN 978-1-4799-2385-4, IEEE catalog no. CFP1441J-AR;

[4] Costache D-Acționări hidraulice și pneumatice la autovehicule, Ed. Academia Militară, București, 1985;

[5] Vasiliu N, Vasiliu D- Acționări hidraulice și pneumatice Vol. 1, București 2004 